\title{
Solusi Numerik Model Matematika SHEIR pada Penyebaran Penyakit Campak dengan Vaksinasi dan Kekebalan Kelompok
}

\author{
Darmawati*1, Masyita Haerianti $^{2}$, Wahyudin Nur ${ }^{3}$, Magfirah ${ }^{4}$ \\ ${ }^{1,3,4}$ Program Studi Matematika, FMIPA, Universitas Sulawesi Barat \\ ${ }^{2}$ Program Studi Keperawatan, FIKES, Universitas Sulawesi Barat \\ e-mail: * darmath@unsulbar.ac.id
}

\begin{abstract}
In this paper, mathematical model of measles transmission dynamics considering vaccination and herd immunity is discussed. The solution of the model is investigated using euler, atangana, dan nonstandard finite difference method. After comparing the solutions of the model, we observe that the solutions obtained by using euler and atangana method diverge for certain step. On the other hand, the solutions obtained by using nonstandard finite difference always converge.
\end{abstract}

Keywords: Numerical schemes, Euler method, Atangana method, Nonstandard finite difference method

\section{PENDAHULUAN}

Penyakit campak adalah penyakit menular yang diakibatkan oleh virus measles (Moss 2017). Penyebarannya melalui droplet dan partikel penularnya dapat bertahan sampai dua jam (Paules, Marston, \& Fauci 2019). Sebelum vaksin campak diperkenalkan, penyakit ini menyebabkan sekitar 2 juta kematian per tahun. Setelah adanya vaksinasi, angka kematian dapat ditekan menjadi sekitar 100 ribu per tahun (Moss 2017). Vaksinasi dianggap sebagai metode terbaik untuk mengendalikan penyebaran penyakit campak (Paules, Marston, \& Fauci 201). Meskipun demikian, masih banyak masyarakat yang tidak mengikuti program vaksinasi. Beberapa model matematika telah membahas masalah vaksinasi dan penyakit campak (Edward 2015)(J. M. \& R. I. 2014). Model tersebut merupakan system persamaan diferensial biasa. Beberapa skema numerik dapat digunakan untuk menentukan solusi numerik model yang dinyatakan dalam system persamaan diferensial biasa. Kita dapat menggunakan metode runge kutta, euler, milne simpson, beda hingga tak standar. Pada tahun, Atangana memperkenalkan sebuah metode baru (Atangana \& İğret Araz 2020). Dalam artikel ini, kami membandingkan beberapa skema numerik yang digunakan untuk menentukan solusi numerik model. Model tersebut adalah metode euler, metode beda hingga tak standar, dan metode Atangana.

\section{METODE PENELITIAN}

Penelitian ini adalah penelitian studi literatur. Berikut merupakan tahapan penelitian yang dilakukan:

- Membangun model matematika

- Menentukan titik kesetimbangan model

- Menentukan bilangan reproduksi dasar

- Menentukan diskritisasi model sesuai metode yang digunakan

- Membuat program dan melakukan simulasi numerik

- Membandingkan hasil ketiga metode 


\section{https://jurnal.unsulbar.ac.id/index.php/saintifik}

\section{HASIL DAN PEMBAHASAN}

Dari hasil penelusuran literatur, diperoleh masalah nyata dan fakta-fakta penyakit Campak. Berdasarkan informasi tersebut, dibangunlah model matematika sebagai berikut:

$$
\begin{aligned}
& \frac{d S_{h}}{d t}=\left(1-\kappa \phi_{n}\right) \rho_{h} \Lambda-\beta S_{h} I-\left(\mu+\kappa \phi_{s}\right) S_{h}, \\
& \frac{d E}{d t}=\beta S_{h} I-(\mu+\sigma) E, \\
& \frac{d I}{d t}=\sigma E-(\mu+\omega) I, \\
& \frac{d R}{d t}=\kappa \phi_{n}\left(1-\rho_{h}\right) \Lambda+\omega I-\mu R+\kappa \phi_{s} S_{h} .
\end{aligned}
$$

dimana:

$S_{H}=$ Manusia rentan yang dapat terinfeksi dan mengandalkan Herd Immunity (anti-vaksin)

$E$ = Manusia yang terekspos penyakit campak

$I$ = Manusia yang terinfeksi dan mampu menularkan penyakit campak

$R=$ Manusia yang sudah kebal terhadap penyakit campak

$\rho_{H}=$ Proporsi masyarakat yang terpapar paham anti-vaksin

$\Lambda=$ Rekrutmen manusia sehat

$\mu=$ Laju kematian alami

$\kappa=$ Efektifitas edukasi

$\phi_{S}=$ Proporsi $S_{H}$ yang mendapat edukasi

$\phi_{n}=$ Proporsi masyarakat umum yang mendapat edukasi

$\sigma=$ Laju transisi E ke I

$\omega=$ Laju kesembuhan.

Dengan menyelesaikan persamaan diferensial di atas, diperoleh titik setimbang model untuk Disease Free Equilibrium (DFE) yaitu:

$$
\begin{aligned}
S_{H}{ }^{*} & =\frac{\rho_{H} \Lambda\left(1-\kappa \phi_{n}\right)}{\mu+\kappa \phi_{S}} \\
E^{*} & =0 \\
I^{*} & =0 \\
R^{*} & =\frac{\kappa \phi_{n}\left(\left(1-\rho_{H}\right) \Lambda\left(\mu+\kappa \phi_{S}\right)\right)+\left(\rho_{H} \Lambda\left(1-\kappa \phi_{n}\right)\right)}{\mu\left(\mu+\kappa \phi_{S}\right)} .
\end{aligned}
$$

Dari hasil ini, selanjutnya digunakan Matrix Next Generation (NGM) untuk mendapatkan nilai $R_{0}$ model. Diperoleh:

Selanjutnya melakukan diskritisasi model.

$$
R_{0}=\frac{\beta \sigma \rho_{H} \Lambda\left(1-\kappa \phi_{n}\right)}{\left(\mu+\kappa \phi_{S}\right)(\mu+\sigma)(\mu+\omega)} .
$$

\subsection{Metode Euler}

Berdasarkan model (1), kita memperoleh sistem berikut:

$$
\begin{array}{ll}
\frac{S_{h}^{(j+1)}-S_{h}^{(j)}}{w} & =\left(1-\kappa \phi_{n}\right) \rho_{h} \Lambda-\beta S_{h}^{(j)} I^{(j)}-\left(\mu+\kappa \phi_{s}\right) S_{h}^{(j)}, \\
\frac{E^{(j+1)}-E^{(j)}}{w} & =\beta S_{h}^{(j)} I-(\mu+\sigma) E^{(j)}, \\
\frac{I^{(j+1)}-I^{(j)}}{w} & =\sigma E^{(j)}-(\mu+\omega) I^{(j)}, \\
\frac{I^{(j+1)}-I^{(j)}}{w} & =\kappa \phi_{n}\left(1-\rho_{h}\right) \Lambda+\omega I^{(j)}-\mu R^{(j)}+\kappa \phi_{s} S_{h}^{(j)} .
\end{array}
$$


https://jurnal.unsulbar.ac.id/index.php/saintifik

Dengan $w$ adalah lebar langkah.Selanjutnya kita mengumpulkan suku yang memiliki indeks $(j+1)$ dan diperoleh hasil diskritisasi berikut:

$$
\begin{array}{ll}
S_{h}^{(j+1)} & =S_{h}^{(j)}+w\left(\left(1-\kappa \phi_{n}\right) \rho_{h} \Lambda-\beta S_{h}^{(j)} I^{(j)}-\left(\mu+\kappa \phi_{s}\right) S_{h}^{(j)}\right), \\
E^{(j+1)} & =E^{(j)}+w\left(\beta S_{h}^{(j)} I-(\mu+\sigma) E^{(j)}\right), \\
I^{(j+1)} & =I^{(j)}+w\left(\sigma E^{(j)}-(\mu+\omega) I^{(j)}\right), \\
R^{(j+1)} & =R^{(j)}+w\left(\kappa \phi_{n}\left(1-\rho_{h}\right) \Lambda+\omega I^{(j)}-\mu R^{(j)}+\kappa \phi_{s} S_{h}^{(j)}\right) .
\end{array}
$$

\subsection{Metode Atangana}

Metode ini adalah metode yang baru diperkenalkan pada tahun 2020. Berbeda dengan metode Euler yang termasuk metode satu langkah, metode ini termasuk metode banyak langkah karena memerlukan beberapa solusi sebelumnya untuk menentukan solusi selanjutnya. Metode Atangana memerlukan tiga solusi sebelumnya untuk menentukan solusi selanjutnya. Kami menggunakan metode Euler untuk menentukan semua nilai awal metode Atangana Berikut merupakan hasil diskritiasi model (1) dengan menggunakan metode Atangana:

Untuk $j=0$ dan $j=1$

$$
\begin{array}{ll}
S_{h}^{(j+1)} & =S_{h}^{(j)}+w\left(\left(1-\kappa \phi_{n}\right) \rho_{h} \Lambda-\beta S_{h}^{(j)} I^{(j)}-\left(\mu+\kappa \phi_{s}\right) S_{h}^{(j)}\right), \\
E^{(j+1)} & =E^{(j)}+w\left(\beta S_{h}^{(j)} I-(\mu+\sigma) E^{(j)}\right), \\
I^{(j+1)} & =I^{(j)}+w\left(\sigma E^{(j)}-(\mu+\omega) I^{(j)}\right), \\
R^{(j+1)} & =R^{(j)}+w\left(\kappa \phi_{n}\left(1-\rho_{h}\right) \Lambda+\omega I^{(j)}-\mu R^{(j)}+\kappa \phi_{s} S_{h}^{(j)}\right) .
\end{array}
$$

Untuk $j=2,3, \ldots ., j_{\max }$

$$
\begin{aligned}
& S_{h}^{(j+1)}=S_{h}^{(j)}+\frac{5}{12}\left[w\left(\left(1-\kappa \phi_{n}\right) \rho_{h} \Lambda-\beta S_{h}^{(j-2)} I^{(j)}-\left(\mu+\kappa \phi_{s}\right) S_{h}^{(j-2)}\right)\right]+ \\
& \frac{4}{3}\left[w\left(\left(1-\kappa \phi_{n}\right) \rho_{h} \Lambda-\beta S_{h}^{(j-1)} I^{(j-1)}-\left(\mu+\kappa \phi_{s}\right) S_{h}^{(j-1)}\right)\right]+ \\
& \frac{23}{12}\left[w\left(\left(1-\kappa \phi_{n}\right) \rho_{h} \Lambda-\beta S_{h}^{(j)} I^{(j)}-\left(\mu+\kappa \phi_{s}\right) S_{h}^{(j)}\right)\right] \\
& E^{(j+1)} \quad=E^{(j)}+\frac{5}{12}\left[w\left(\beta S_{h}^{(j-2)} I-(\mu+\sigma) E^{(j-2)}\right)\right]+ \\
& \frac{4}{3}\left[w\left(\beta S_{h}^{(j-1)} I-(\mu+\sigma) E^{(j-1)}\right)\right]+ \\
& \frac{23}{12}\left[w\left(\beta S_{h}^{(j)} I-(\mu+\sigma) E^{(j)}\right)\right] \\
& I^{(j+1)} \quad=I^{(j)}+\frac{5}{12}\left[w\left(\sigma E^{(j-2)}-(\mu+\omega) I^{(j-2)}\right)\right]+ \\
& \frac{4}{3}\left[w\left(\sigma E^{(j-1)}-(\mu+\omega) I^{(j-1)}\right)\right]+ \\
& \frac{23}{12}\left[w\left(\sigma E^{(j)}-(\mu+\omega) I^{(j)}\right)\right] \\
& R^{(j+1)}=R^{(j)}+\frac{5}{12}\left[w\left(\kappa \phi_{n}\left(1-\rho_{h}\right) \Lambda+\omega I^{(j-2)}-\mu R^{(j-2)}+\kappa \phi_{s} S_{h}^{(j-2)}\right)\right]+ \\
& \frac{4}{3}\left[w\left(\kappa \phi_{n}\left(1-\rho_{h}\right) \Lambda+\omega I^{(j-1)}-\mu R^{(j-1)}+\kappa \phi_{s} S_{h}^{(j-1)}\right)\right]+ \\
& \frac{23}{12}\left[w\left(\kappa \phi_{n}\left(1-\rho_{h}\right) \Lambda+\omega I^{(j-1)}-\mu R^{(j-1)}+\kappa \phi_{s} S_{h}^{(j-1)}\right)\right] .
\end{aligned}
$$

Solusi Numerik Model matematika SHEIR pada Penyebaran Penyakit Campak dengan Vaksinasi dan Kekebalan Kelompok (Darmawati,dkk) 
https://jurnal.unsulbar.ac.id/index.php/saintifik

3.3 Metode beda hingga tak standar

Berdasarkan model (1), kami memperoleh

$$
\begin{array}{ll}
\frac{S_{h}^{(j+1)}-S_{h}^{(j)}}{\zeta(w)} & =\left(1-\kappa \phi_{n}\right) \rho_{h} \Lambda-\beta S_{h}^{(j+1)} I^{(j)}-\left(\mu+\kappa \phi_{s}\right) S_{h}^{(j+1)}, \\
\frac{E^{(j+1)}-E^{(j)}}{\zeta(w)} & =\beta S_{h}^{(j+1)} I^{(j)}-(\mu+\sigma) E^{(j+1)}, \\
\frac{I^{(j+1)}-I^{(j)}}{\zeta(w)} & =\sigma E^{(j+1)}-(\mu+\omega) I^{(j+1)}, \\
\frac{R^{(j+1)}-R^{(j)}}{\zeta(w)} & =\kappa \phi_{n}\left(1-\rho_{h}\right) \Lambda+\omega I^{(j+1)}-\mu R^{(j+1)}+\kappa \phi_{s} S_{h}^{(j+1)} .
\end{array}
$$

Setelah melakukan penyusunan kembali, diperoleh hasil diskritisasi berikut:

$$
\begin{aligned}
S_{h}^{(j+1)} & =\frac{\zeta(w)\left(1-\kappa \phi_{n}\right) \rho_{h} \Lambda+S_{h}^{(j)}}{1+\beta I^{(j)} \zeta(w)+\left(\mu+\kappa \phi_{s}\right) \zeta(w)} \\
E^{(j+1)} & =\frac{\zeta(w) \beta S_{h}^{(j+1)} I^{(j)}+E^{(j)}}{1+\zeta(w)(\mu+\sigma)}, \\
I^{(j+1)} & =\frac{I^{(j)}+\zeta(w) \sigma E^{(j+1)}}{1+\zeta(w)(\mu+\omega)}, \\
R^{(j+1)} & =\frac{\kappa \phi_{n}\left(1-\rho_{h}\right) \Lambda \zeta(w)+\omega I^{(j+1)} \zeta(w)+\zeta(w) \kappa \phi_{s} S_{h}^{(j+1)}+R^{(j)}}{1+\mu \zeta(w)},
\end{aligned}
$$

\begin{tabular}{|c|c|c|c|}
\hline Step & Metode Euler & Metode Atangana & Metode NSFD \\
\hline \multirow[b]{2}{*}{0.1} & Tidak konvergen & Tidak konvergen & Konvergen \\
\hline & & & \\
\hline 000 & & & \\
\hline $0 \Omega 8$ & & & leanureman \\
\hline \multirow[b]{3}{*}{0.072} & 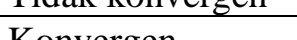 & 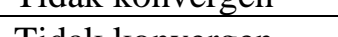 & Kuineigen \\
\hline & Konvergen & Tidak konvergen & Konvergen \\
\hline & & & \\
\hline 007 & lonuoron & Tidok kanyorgan & lronyeraen \\
\hline 006 & konyeroen & Tidak konveroen & konveroen \\
\hline 0.00 & Konveigen & 1 1dak Konvergen & Konvergen \\
\hline
\end{tabular}

dengan

$$
\zeta(w)=\frac{e^{\mu w}-1}{\mu} .
$$

Hasil simulasi numerik dengan menggunakan ketiga skema numerik di atas disajikan dalam tabel berikut.

- Untuk $R_{0}<1$ 
https://jurnal.unsulbar.ac.id/index.php/saintifik

\begin{tabular}{|c|l|l|l|}
\hline & Konvergen & Konvergen & Konvergen \\
0.0184 & & & \\
& & & \\
& & & \\
\hline 0.018 & konvergen & konvergen & konvergen \\
\hline 0.01 & konvergen & konvergen & konvergen \\
\hline 0.009 & konvergen & konvergen & konvergen \\
\hline
\end{tabular}

- $\quad$ Untuk $R_{0}>1$

\begin{tabular}{|c|c|c|c|}
\hline Step & Metode Euler & Metode Atangana & Metode NSFD \\
\hline \multirow{3}{*}{0.1} & Tidak konvergen & Tidak konvergen & Konvergen \\
\hline & & & \\
\hline & & & \\
\hline 0.09 & Tidak konvergen & Tidak konvergen & konvergen \\
\hline 0.08 & Tidak konvergen & Tidak konvergen & konvergen \\
\hline 0.07 & Tidak Konvergen & Tidak konvergen & konvergen \\
\hline 0.06 & Tidak Konvergen & Tidak konvergen & konvergen \\
\hline \multirow{3}{*}{0.058} & Konvergen & Tidak konvergen & konvergen \\
\hline & & & \\
\hline & 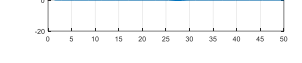 & s: & 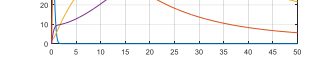 \\
\hline 0.05 & konvergen & Tidak konvergen & konvergen \\
\hline \multirow{3}{*}{0.015} & Konvergen & Konvergen & Konvergen \\
\hline & & & \\
\hline & 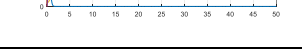 & 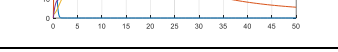 & 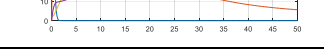 \\
\hline 0.01 & konvergen & konvergen & konvergen \\
\hline 0.009 & konvergen & konvergen & konvergen \\
\hline
\end{tabular}

Dari hasil simulasi di atas, dapat dilihat bahwa metode yang paling baik untuk mempelajari solusi numerik suatu model adalah dengan metode NSFD, karena metode ini selalu konvergen. Dua metode lainnya hanya konvergen pada step tertentu.

\section{KESIMPULAN}

Metode-metode yang dibandingkan, semuanya dapat digunakan pada model epidemic. Akan tetapi dari 3 (tiga) metode yang dibandingkan, Metode NSFD memberikan hasil yang jauh lebih baik karena metode ini selalu konvergen. 
https://jurnal.unsulbar.ac.id/index.php/saintifik

\section{DAFTAR PUSTAKA}

Atangana A., İgret Araz S. 2020 New numerical method for ordinary differential equations: Newton polynomial. Journal of Computational and Applied Mathematics, 372, 112622. https://doi.org/10.1016/j.cam.2019.112622

Edward S. 2015 A Mathematical Model for Control and Elimination of the Transmission Dynamics of Measles. Applied and Computational Mathematics, 4(6), 396. https://doi.org/10.11648/j.acm.20150406.12

J. M. O., R. I. G. 2014 A Mathematical Model of Measles with Vaccination and Two Phases of Infectiousness. IOSR Journal of Mathematics, 10(1), 95-105. https://doi.org/10.9790/5728-101495105

Moss W. J. 2017 Measles. The Lancet, 390(10111), 2490-2502. https://doi.org/10.1016/S01406736(17)31463-0

Paules C. I., Marston H. D., Fauci A. S. 2019 Measles in 2019 - Going Backward. New England Journal of Medicine, 380(23), 2185-2187. https://doi.org/10.1056/NEJMp1905099 